\title{
8th European Conference on Clinical Aspects and Treatment of HIV Infection, Athens, 28-31 October 2001
}

$\mathrm{T}$ e conference was set in the Astir Hote Resort on the peninsula at the outskirts of Athens, overlooking the Phaleron Bay. It was officially opened by Dr Christine Katlama, president of the European AIDS Clinical Society, and Professor John Kosmidis, the conference chairman. The European Clinical Guidelines for HIV management, written by the European AIDS Clinical Society (EACS), was launched at the conference.

The main focus of many delegates was on new antiretroviral drugs. The star of the conference was tenofovir disoproxil fumarate, a single tablet, once daily nucleotide developed by Gilead Sciences. It has potent activity against multidrug nucleoside resistant HIV with the exception of T69 insertion, which is fortunately rare ( $1 \%$ of all patients). At 24 weeks, adding tenofovir to treatment experienced patients with detectable viral load achieved significant and durable viral suppression compared with placebo $(-0.61$ versus $-0.03 \log _{10}$ copies $/ \mathrm{ml}$ ), with $22 \%$ reaching viral load $<50$ copies $/ \mathrm{ml}$ (versus $1 \%$ in placebo group). No in vitro mitochondrial toxicity has been observed so far. An expanded access programme has since been launched in the United Kingdom.

Atazanavir (BMS) is a potent once daily protease inhibitor that does not appear to elevate cholesterol or triglyceride at 48 weeks, and has comparable efficacy to nelfinavir. However, a rise of indirect bilirubin occurs, though the clinical significance of this is uncertain. Data on tipranavir, the first nonpeptidic protease inhibitor, were presented at the Boehringer Ingelheim satellite symposium. It is active against multiple resistant virus, though side effects can be significant when boosted with ritonovir.

A presentation from Roche-Trimeris on fusion inhibitors showed $39 \%$ of 41 heavily pretreated patients achieving $<400$ copies $/ \mathrm{ml}$ viral load after completing 48 weeks of T20 twice daily injection. Phase III studies are in progress, but are hampered by difficulty in producing large quantities of amino acid peptides. T-1249, currently under investigation, has in vitro activity against T-20 resistant virus and may be used once daily.

Encouraging data were presented on the management of co-infection of hepatitis C and HIV. Jurgen Rockstroh from Germany showed that $95 \%$ of haemophiliacs, $50-90 \%$ of drug users, and $6 \%$ of homosexual men under his care are co-infected. The rate of hepatitis C replication is independently correlated with raising HIV viral load and falling CD4 counts. Rates of death, liver failure, and cirrhosis in patients with hepatitis $C$ are higher in those who are HIV positive, and this risk is greates with hepatitis $\mathrm{C}$ genotype 1 . Weekly pegalated interferon together with ribavirin, was effective at controlling, and in $40 \%$ of cases eradicating, hepatitis $\mathrm{C}$ genotypes 2 and 3 (Pegasus study).

Pathogenesis of the lipid disorders associated with HIV infection and its treatment is becoming clearer. There is an interaction between the effect of the nucleoside reverse transcriptase inhibitors (stavudine possibly more than zidovudine), the protease inhibitors and HIV infection per se. Insulin resistance is generated by long term use of protease inhibitors and precedes changes in body composition. The PPAR $-\gamma$ agonist rosigliterzone seems to be effective in reversing insulin resistance in vitro and shows promise. Studies of growth hormones and steroids have been disappointing. The use of routine lactate measurement as a predictor of mitochondrial toxicity or lactic acidosis has not been established.

At this conference EACS also announced that scholarships were given to seven young clinicians from countries with limited resources to be trained in HIV centres in Europe. In addition, 29 bursaries were given to doctors for attendance at this conference. A special welcome was also given to American delegates who came to Europe despite world events. The conference closed with a presentation from Joep Lange of the Netherlands on efforts in treating HIV in developing countries

Adrian Palfreeman

Department of GU Medicine Peterborough District Hospital, Peterborough PE3 6DA, UK

Mia Huengsberg Whittall Street Clinic, Birmingham B4 6DH, UK 